\title{
$\nabla$
}

\section{Dermoscopic clues in the diagnosis of amelanotic and hypomelanotic malignant melanoma}

\author{
Pistas dermatoscópicas no diagnóstico de melanoma maligno \\ amelanótico e hipomelanótico
}

\author{
Raquel Bissacotti Steglich ${ }^{1}$ \\ Mariana Silveira Ferreira ${ }^{2}$ \\ André Vicente Esteves de Carvalho ${ }^{4}$
}

\author{
Carolina Degeon Meotti ${ }^{1}$ \\ Louise Lovatto ${ }^{3}$ \\ Carlos Gustavo Carneiro de Castro ${ }^{5}$
}

\begin{abstract}
The clinical identification of amelanotic malignant melanoma (AMM) and hypomelanotic malignant melanoma (HMM) becomes difficult due to the lack of pigmentation and to the diverse clinical presentations. Dermoscopy is very useful in these cases, increasing the level of suspicion of malignancy. We report 4 cases of amelanotic malignant melanoma and hypomelanotic malignant melanoma with characteristic dermoscopic findings. Dermoscopy under polarized light demonstrates vascular polymorphism, globules and milky-red areas, in addition to chrysalis and multiple blue-gray dots.

Keywords: Dermoscopy; Diagnosis; Diagnosis, differential; Melanoma; Melanoma, amelanotic

Resumo: A identificação clínica de melanoma maligno amelanótico e hipomelanótico torna-se difícil devido à falta de pigmentação e às diversas apresentações desse tipo de tumor. A dermatoscopia é muito útil nestes casos, aumentando o grau de suspeição de malignidade. Relatamos 4 casos de melanoma maligno amelanótico e melanoma maligno hipomelanótico com achados dermatoscópicos característicos. A dermatoscopia com luz polarizada demonstra polimorfismo vascular, glóbulos e áreas vermelholeitosas, assim como crisálides e múltiplos pontos azul-acinzentados.

Palavras-chave: Dermoscopia; Diagnóstico; Diagnóstico diferencial; Melanoma; Melanoma amelanótico
\end{abstract}

\section{INTRODUCTION}

The incidence of cutaneous melanoma has increased considerably during the last decades in the whole world. ${ }^{1}$ Its aggressive behavior and the difficulty to treat in advanced stages makes early diagnosis crucial. $^{2}$

AMM and HMM lesions represent approximately 2 to $8 \%$ of all melanomas, presenting without or with little pigmentation, respectively. ${ }^{3,45}$ The scarcity of pigmentation makes these type of tumor hard to identify, making clinical diagnosis difficult. Dermoscopy is a major instrument allowing the evaluation of pigment, and above all determining characteristic vascular structures, unseen by naked eye. ${ }^{3}$ Such vascular patterns have an important role on the suspicion of melanoma in doubtful nonpigmented lesions.

\section{CASE REPORTS}

Patient 1: A 55-year-old female shows an infiltrated, pseudo-vesicular plaque with well defined borders, $2 \times 1,5 \mathrm{~cm}$ of diameter, on the proximal region of

Received on 20.09.2011.

Approved by the Advisory Board and accepted for publication on 10.02.2012.

* Work performed at the Irmandade da Santa Casa de Misericórdia de Porto Alegre (ISCMPA) - Porto Alegre (RS), Brazil.

Conflict of interest: None

Financial funding: None

M.D., Dermatologist. Member of the Brazilian Society of Dermatology - Porto Alegre (RS), Brazil.

Medical student. - Medical student at the Federal University of Rio Grande do Sul (UFRGS) - Porto Alegre (RS), Brazil.

Master of Medical Clinical Sciences, University of Barcelona, Spain. - Dermatologist at the Irmandade da Santa Casa de Misericórdia de Porto Alegre (ISCMPA) - Porto Alegre (RS), Brazil.

Masters Degree in Pathology - Federal University of Health Sciences of Porto Alegre (UFCSPA) - Porto Alegre (RS), Brazil. - Dermatology preceptor at the

Irmandade da Santa Casa de Misericórdia de Porto Alegre (ISCMPA) - Porto Alegre (RS), Brazil.

Medical Doctor - Specialist in Dermatology - Private practice - Rio de Janeiro (RJ), Brazil. 
the left arm (Figure 1). Small erythematous papules are seen on the periphery of the lesion. Dermoscopy under polarized light (DPL): chrysalis, linear-irregular vessels, globules and milky-red areas (Figures 2 and 3). Histopathology: nodular AMM, Breslow 11,0 mm, Clark V, with epidermotropic melanoma metastasis. Simultaneously, presents basal cell carcinoma (BCC) on the frontal region.

Patient 2: A 63-year-old male with a history of BCC and squamous cell carcinoma (SCC) in the past presents with an erythematous papule with a bright and smooth surface on the left flank (Figure 4A). DPL: milky-red areas and globules, linear-irregular vessels and residual blue pigmentation (Figure 4B). The contact dermoscopic exam shows disappearance of the central pinkish area and consequent white structureless area (Figure 4C). Histopathology: nodular HMM,

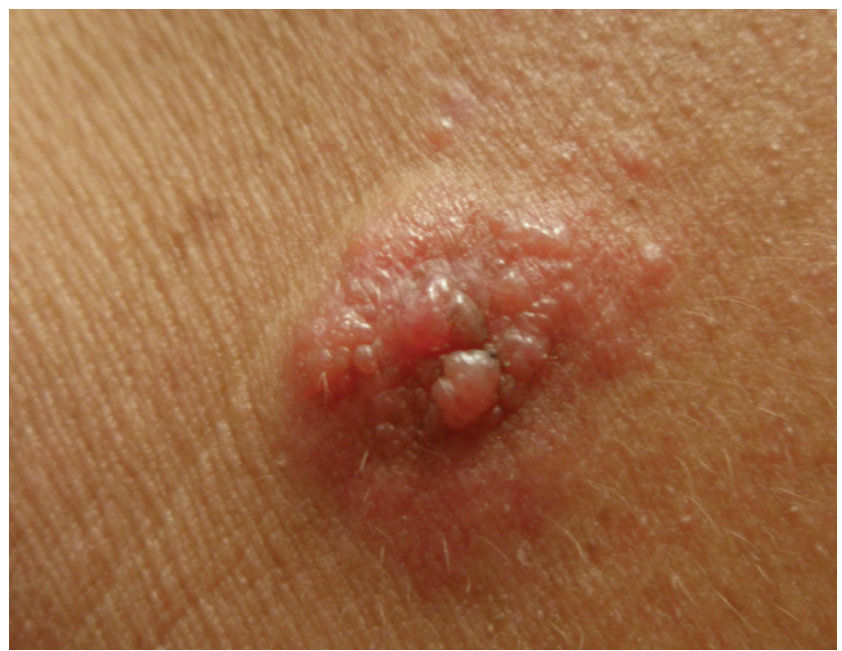

FIGURE 1: Erythematous plaque with an irregular surface on the left arm with satellite small papules

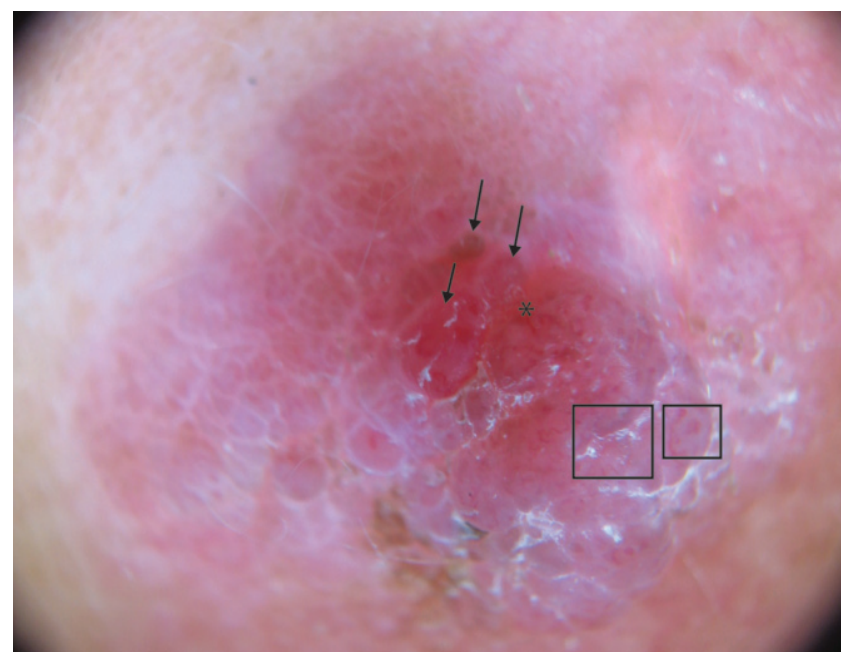

FIGURE 2: Dermoscopic image shows linear-irregular vessels (square), milky-red areas (asterisk) and globules (arrows)
Breslow 2,5 mm, Clark IV. BCC and SCC on the trunk.

Patient 3: A 65-year-old male with history of previous melanoma and BCC presents with an erythematous plaque, $1,0 \mathrm{~cm}$ in diameter, on the left scapular region. DPL: milky-red areas, central depigmentation, peripheral brown structureless area, dotted and linear-irregular vessels (Figure 5). Histopathology: superficial spread HMM on vertical growing stage, Breslow 1,16 mm , Clark IV.

Patient 4: A 63-year-old female with history of previous BCC shows on her left thigh a $1,6 \times 1,5 \mathrm{~cm}$ erythematous plaque, with a nodule on its inferior portion. Dark-blue areas are seen on less than $25 \%$ of the lesion (Figure 6). DPL: milky red areas, linear irregular vessels, remaining dark-blue pigmentation and chrysalis (Figure 7 and 8). Histopathology: nodular ulcerated HMM, Breslow 3,3 mm, Clark IV.

\section{DISCUSSION}

AMM and HMM present as primary melanomas, recurrent melanomas or metastasis of pigmented primary melanomas. These lesions can occur without the features commonly seen in other melanomas, such as asymmetry and altered pigmentation, often leading to misdiagnosis and inappropriate treatment. ${ }^{5,6}$ Dermoscopic evaluation has been shown to be superior to naked eye examination for the diagnosis of AMM and HMM. ${ }^{3}$

Residual pigmentation can be seen as blue or grayish areas, pigment network and brown, gray or black dots and globules. ${ }^{7}$ Upon dermoscopic inspection AMM have no melanin pigmentation (light brown, dark brown, blue, gray, black). HMM may present as partially pigmented lesions with melanin pigmentation area of less than $25 \%$ of the total surface area; or as light-colored lesions with only light brown,

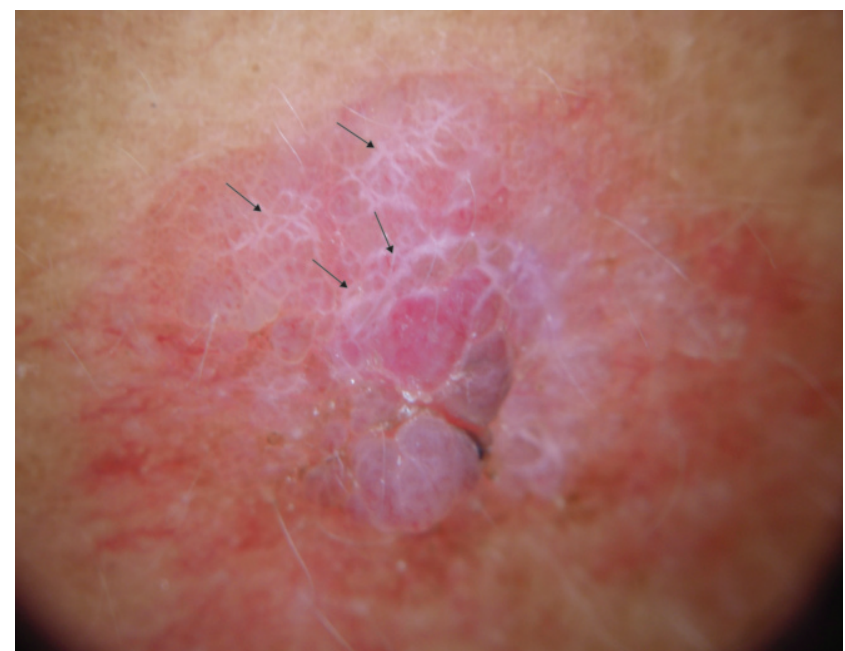

FIGURE 3: Dermoscopic evaluation revealing chrysalis (arrows) 

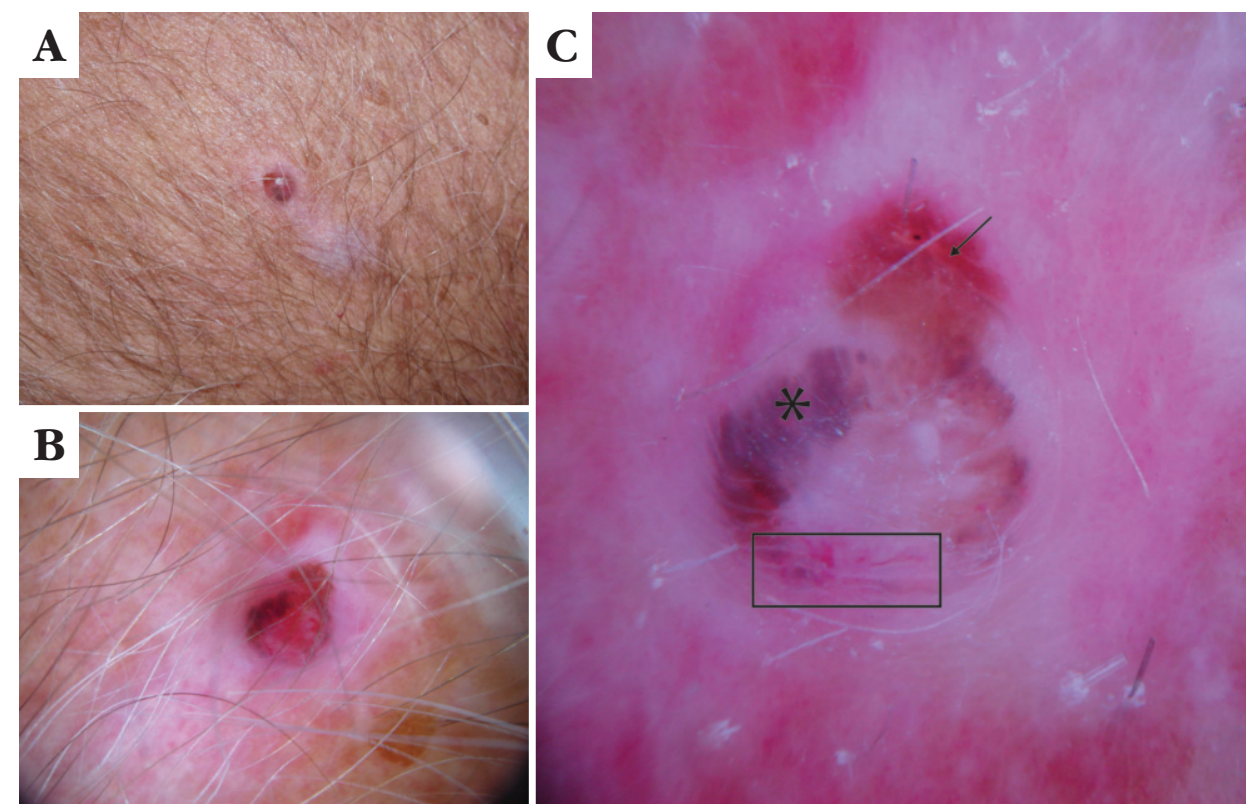

Figure 4: (A) Erythematous papule on the left flank. (B) Vascular polymorphism and residual pigmentation at dermoscopy. (C) Dermoscopic examination shows vascular polymorphism (square), blue residual pigmentation (asterisk) and milky-red areas (arrow)

light blue, or light gray pigmentation that may occupy more than $25 \%$ of total surface area - no dark brown, deep blue, or black pigmentation is found. ${ }^{3}$

Macroscopically, AMM and HMM can be confused with BCC, SCC, Paget's disease and benign lesions of dermatitis, pyogenic granuloma and plantar wart. ${ }^{4}$ The reported patients had history or coexistence of BCC and/or SCC. Dermoscopic evaluation was essential for the correct diagnostic suspicion and proper management.

Vascular pattern can increase the level of suspicion of AMM and HMM and it varies according to the level of invasion of the melanoma. ${ }^{7,8,9}$ Melanoma can initially show dotted vessels and, as the thickness increases, the vascular polymorphism increases with hairpin and linear-irregular vessels associated with milky-red areas, reticular depigmentation and chrysalis. ${ }^{8}$ Such vascular patterns can only be accurately determined through dermoscopic examination of the lesions. Considering the reported cases on this article, the only cases that presented chrysalis were the patients 1 and 4, who presented the thickest tumors (Breslow 11,0 $\mathrm{mm}$ and 3,3 $\mathrm{mm}$ ).

Several dermoscopic vascular patterns are observed in different types of benign and malignant tumors. ${ }^{8}$ Dotted vessels represent a significant marker
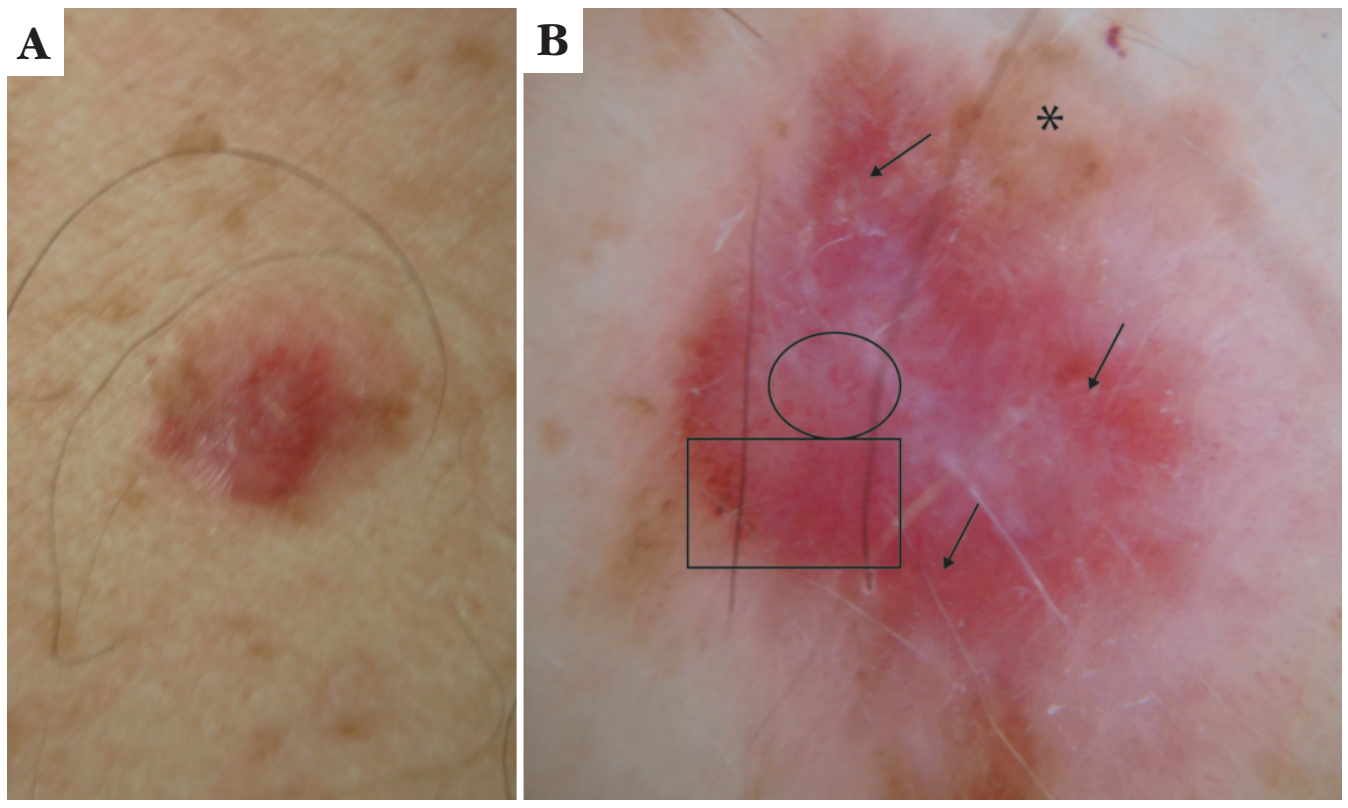

Figure 5: (A) Erythematous plaque on the left scapular region. (B) Milky red areas (arrows), central depigmentation, brown structureless area at the periphery (asterisk), linear-irregular vessels (circle) and dotted vessels (square) 


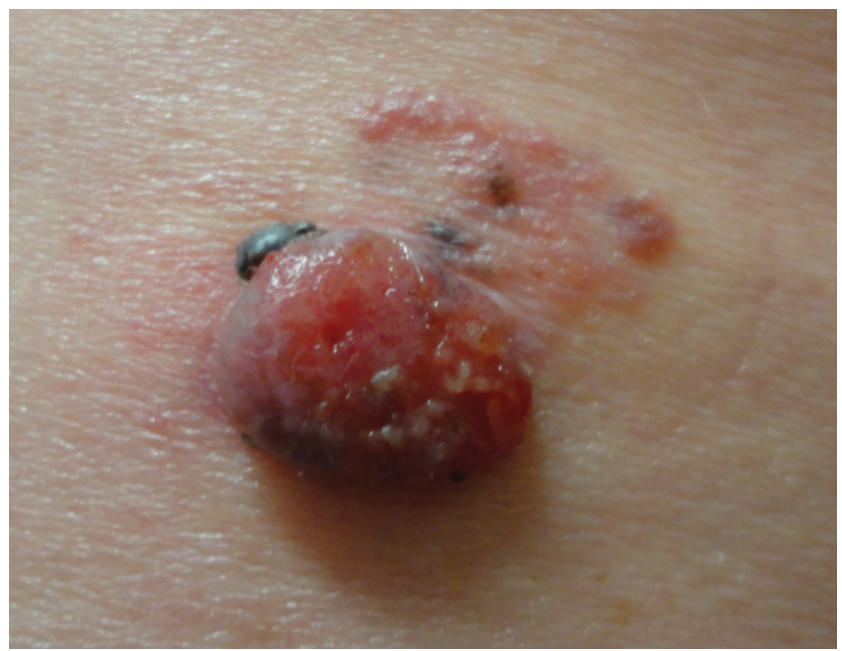

FiguRE 6: Erythematous plaque, with a nodule on its inferior portion. Some dark-blue areas are seen on less than $25 \%$ of the lesion

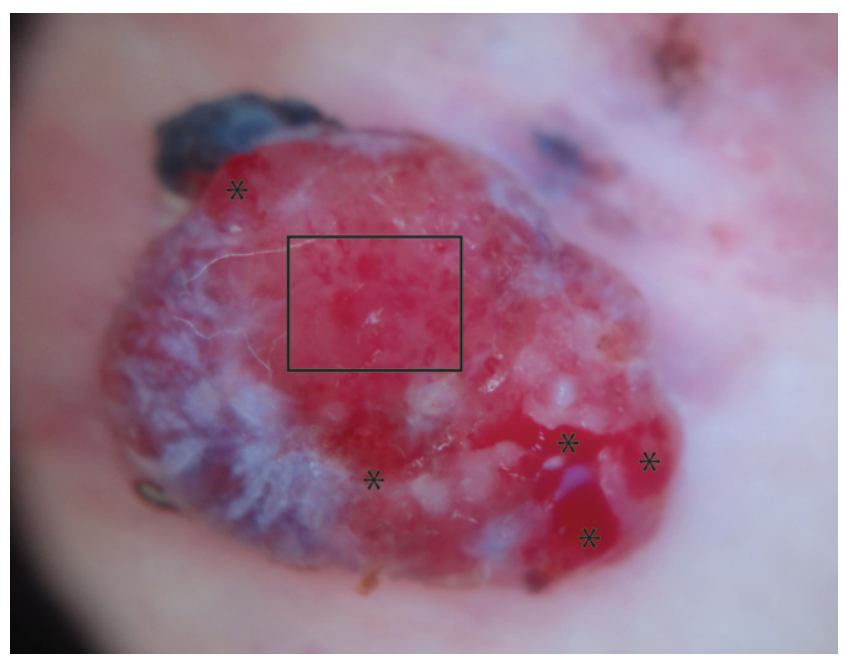

FiguRE 7: The non-contact dermoscopic exam shows milky red areas (asterisk), atypical vessels (square)

\section{REFERENCES}

1. Maia M, Russo C, Ferrari N, Ribeiro MCSA. Acral lentiginous melanoma: a challenge for early diagnosis. An Bras Dermatol. 2003;78:553-60.

2. Rezze GG, Soares de Sá BC, Neves RI. Dermatoscopia: 0 método de análise de padrões. An Bras Dermatol. 2006;81:261-8.

3. Menzies SW, Kreusch J, Byth K, Pizzichetta MA, Marghoob A, Braun R, et al. Dermoscopic evaluation of amelanotic and hypomelanotic melanoma. Arch Dermatol. 2008;144:1120-7.

4. de Giorgi V, Sestini S, Massi D, Maio V, Giannotti B. Dermoscopy for "true" amelanotic melanoma: A clinical dermoscopy-pathologic case study. J Am Acad Dermatol. 2006:54:341-4.

5. Moloney FJ, Menzies SW. Key points in the dermoscopic diagnosis of hypomelanotic melanoma and nodular melanoma. J Am Acad Dermatol. 2011;38:10-15.

6. Puig S, Argenziano G, Zalaudek I, Ferrera G, Palou J, Massi D, et al. Melanomas that failed dermoscopic detection: a combined clinicodermoscopic approach for not missing melanoma. Dermatol Surg. 2007;33:1262-73.

7. Zalaudek I, Kreusch J, Giacomel J, Ferrara G, Catricalà C, Argenziano G. How to diagnose nonpigmented skin tumors: a review of vascular structures seen with dermoscopy: part I. Melanocytic skin tumors. J Am Acad Dermatol. 2010;63:361-74.

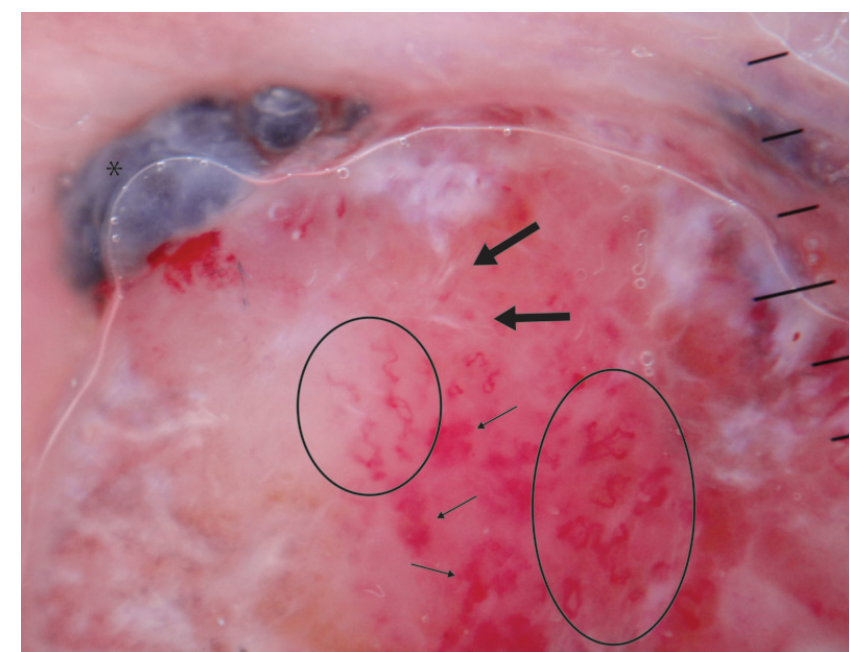

FIGURE 8: The contact dermoscopic exam shows milky red areas (arrows), linear irregular vessels (circle), remaining dark-blue pigmentation (asterisk) and chrysalis (bold arrow)

of melanocytic lesions, with a positive predictive value (PPV) of 90\%, and are considered the best dermatoscopic indicator of the melanocytic origin of a tumor. This vascular pattern can be the only clue to suspect a AMM, however, it can not be considered a pathognomonic sign, since it is present in benign lesions. ${ }^{4,79}$ Irregular linear vessels and milky-red areas have a PPV of $68 \%$ and $77 \%$ in the diagnosis of melanoma, respectively. ${ }^{8}$

The combination of dotted vessels and linear irregular vessels presents itself as the most frequent dermoscopic finding of AMM. ${ }^{3,4}$ Although AMM and HMM are still a challenge in clinical practice, dermoscopy can reveal characteristic vascular structures, improving the diagnostic accuracy and being the key to the diagnosis of melanoma. This technique should be used routinely not only to pigmented but also to doubtful nonpigmented lesions.

8. Argenziano G, Zalaudek I, Corona R, Sera F, Cicale L, Petrillo G, et al. Vascula Structures in Skin Tumors: A Dermoscopy Study. Arch Dermatol. 2004;140:1485-9.

9. Pizzichetta MA, Canzonieri V, Massarut S, Baresic T, Borsatti E, Menzies SW. Pitfalls in the dermoscopic diagnosis of amelanotic melanoma. J Am Acad Dermatol. 2010;62:893-4

\author{
MAILING ADDRESS: \\ Raquel Bissacotti Steglich \\ Irmandade da Santa Casa de Misericórdia de \\ Porto Alegre \\ Rua Professor Annes Dias, 295. \\ 90020-090 - Porto Alegre, RS \\ E-mail: raquelsteglich@yaboo.com.br
}

How to cite this article: Steglich RB, Meotti CD, Ferreira MS, Lovatto L, Carvalho AVE, Castro CGC. Dermoscopic clues in the diagnosis of amelanotic and hypomelanotic malignant melanoma. An Bras Dermatol. 2012;87(6):920-3. 